ARTIGO

DOI: https://doi.org/10.22481/praxis.v15i31.4680

\title{
EDUCAÇÃO AMBIENTAL E JOGOS ELETRÔNICOS: O REAL E VIRTUAL EM TEMPOS CONTEMPORÂNEOS
}

\author{
ENVIRONMENTAL EDUCATION AND ELECTRONIC GAMES: THE REAL AND \\ VIRTUAL IN CONTEMPORARY TIMES
}

\section{EDUCACIÓN AMBIENTAL Y JUEGOS ELECTRÓNICOS: LO REAL Y VIRTUAL EN TIEMPOS CONTEMPORÁNEO}

\author{
Elisângela Barbosa Madruga \\ Universidade Federal do Rio Grande - Brasil \\ Paula Corrêa Henning \\ Universidade Federal do Rio Grande - Brasil
}

\begin{abstract}
Resumo: Frente a um contexto de crises e de tecnologias de informação avançadas, verdades são proliferadas e assim, como uma onda que captura e envolve, muitos submergem a estas. Nesse sentido, o presente artigo tem como proposta analisar teoricamente o tema Educação Ambiental e jogos eletrônicos, pois se entende que ambos são mecanismos de controle e de modulação de sujeitos. Cabe ressaltar que o trabalho se constitui em uma pesquisa bibliográfica. As discussões serão explanadas mediante a provocações advindas do campo da filosofia, que visam disparar um pensamento que se distancie das verdades dadas. A partir do tema em questão, se abordou os conceitos de governamento, noopolítica e ecopolítica, que refletem as novas relações de poder instauradas neste tempo.
\end{abstract}

Palavras-chaves: Educação. Educação Ambiental. Governamento.

Abstract: Facing a crisis context and advanced information technologies, truths are proliferating, and so, like a wave that captures and involves, many submerge. In this sense, this article has as its proposal to analyze theoretically the Environmental Education theme and electronic games, because we understand that both are control mechanisms and modulation of subject. It is worth noting that the work constitutes a bibliographical research. The discussions will be contained by the provocations coming from the field of philosophy, aimed at raising a thought out of the truths given. From the topic in question, if has addressed the concepts of governance, noopolitics and ecopolitics, that reflect the new power relations established at this time. 
Keywords: Education. Environmental education. Governance.

Resumen: Con el contexto de crisis y de tecnologías de información avanzadas, verdades son proliferadas y así como una ola que captura y envuelve, muchos sumergen en ellas. En este sentido, este artículo se propone a analizar teóricamente el tema Educación Ambiental y juegos electrónicos porque se entiende que ambos son mecanismos de control y modulación de sujetos. Este trabajo se constituye en una investigación bibliográfica. Las discusiones ocurrirán por intermedio de las provocaciones del campo de la filosofía, que pretenden disparar un pensamiento que se aleje de las verdades puestas. A partir del tema en cuestión, los conceptos de gobernación, noopolítica y ecopolítica fueron abordados, pues reflejan las nuevas relaciones de poder instauradas en este tiempo.

Palabras clave: Educación. Educación Ambiental. Gobernación.

\section{Introdução}

As inovações tecnológicas que atravessam nosso tempo decorrem de um mundo que buscou constantemente avanços em diversas áreas do conhecimento que possibilitassem a chamada "saída de um estado primitivo" para um "intelectualmente elevado". Uma transformação que objetivou aliviar as dores da sociedade. Constituem-se em ações que ganham potência com sujeitos, grupos e públicos ${ }^{1}$, que são identificados, rastreados, controlados e conectados entre si a redes em tempo real. Nichos de sujeitos que se tornam públicos seletos, que são conquistados pelo discurso do "bem", a saber, do "outro", do ambiente e do planeta.

Frente a tal contexto, o presente artigo tem como proposta discutir teoricamente o tema Educação Ambiental e jogos eletrônicos, pois se entende que ambos são mecanismos de controle e de modulação de sujeitos na atualidade. Tratando-se de uma pesquisa bibliográfica buscou-se investir em referenciais que embasassem tal discussão. O estudo é um recorte de uma pesquisa mais ampla que vem sendo desenvolvida desde de 2016, que visa pensar não somente a inserção de jogos eletrônicos comerciais em sala de aula, mas também olhar os discursos de crise ambiental, de tábua de salvação para a educação, que são acionados a partir deste artefato para capturar, educar e conduzir diversos sujeitos. Para discorrer o tema em

\footnotetext{
${ }^{1}$ Segundo Tarde (2005, p. 2), “o público [...] é uma multidão dispersa, em que a influência dos espíritos uns sobre os outros tornou-se uma ação a distância, a distâncias cada vez maiores".
} 
questão, serão abordados três conceitos que refletem as novas relações de poder instauradas neste tempo. Tratam-se dos conceitos de governamento, noopolítica e ecopolítica.

Primeiramente, expor-se-á o conceito de governamento, para se entender como se dá a condução das condutas dos sujeitos através de mecanismos, como por exemplo, jogos eletrônicos. A ideia de governamento é tomada pelos estudos desenvolvidos por Alfredo Veiga-Neto (2005a), que faz um desdobramento do conceito de governo, trabalhado por Michel Foucault no final da década de 1970. Evidentemente, o filósofo francês também é assumido como ferramenta teórica desse trabalho. Tentar-se-á aproximar o conceito de governamento, acompanhada de Veiga-Neto (2011a), Michel Foucault (2008; 2009; 2010; 2014; 2015) e Maurizio Lazzarato (2006), ao conceito de público, de Gabriel Tarde (2005). Na sequência, será abordado o conceito de noopolítica desenvolvido por Lazzarato (2006). Ao desdobrar o conceito de biopolítica desenvolvido por Foucault (2010a), o autor mostra um poder que surge para agir, não no corpo, mas na mente. Por último apresentar-se-á o conceito de ecopolítica desenvolvido por Edson Passetti (2013) e de ecogovernamentalidade, de Sébastien Malette (2011). Ecopolítica é um desdobramento de biopolítica (PASSETTI, 2013), e se configura como prática de governamento do planeta; enquanto a ecogovernamentalidade vem ser a reorganização da governamentalidade (FOUCAULT, 2008), que se junta à emergência da ecopolítica.

Nesse sentido, oportunizam a construção de um pensamento rebelde, de um ponto de vista específico, de uma perspectiva determinada para tratar das questões e dos problemas que se apresentam na sociedade. O papel desses autores e seus conceitos no presente artigo não será o de abrir portas, mas o de dar algumas chaves para que se possa abrir possibilidades para se pensar a Educação e a Educação Ambiental. Ressalta-se que esta pesquisa não pretende dizer o que tem que ser feito, nem como não fazer, mas se propõe, precipuamente, a pensar de outros modos alguns elementos destes campos de saber.

Tais questões permitem observar uma racionalidade neoliberal ${ }^{2}$ que tem imperado na Educação. Uma racionalidade que cria modelos, legitima verdades e representações para os sujeitos escolarizados. Uma Educação universal, homogênea, que visa cada vez mais reduzir as diferenças. Muitas vezes, essa Educação é pensada em grande escala, contemplando apenas os interesses de corporações. Tal visão fomenta um discurso tão recorrente na atualidade, o de todos por uma Educação de qualidade. E é na busca por determinada qualidade que os jogos eletrônicos, como o Minecraft, que é financiado e distribuído pela empresa Microsoft, se

\footnotetext{
${ }^{2}$ Segundo Veiga-Neto (2011a, p. 38), "[...] no sistema neoliberal a liberdade deve ser continuamente produzida e exercitada sob a forma de competição".
} 
tornam ferramentas importantes para elaboração de propostas pedagógicas para a sala de aula (ZH NOTICIAS, 2013, s/p).

Nessa perspectiva, intenciona-se instigar provocações em torno dos mecanismos que capturam e conduzem a conduta de muitos. Os engendramentos e as táticas de gerenciamento da vida que se atualizaram para ressurgirem como novas maneiras "[...] de garantir o controle social, com métodos menos agressivos, mas não menos eficazes" (BAUMAN; BORDONI, 2016, p. 27). Estratégias convidativas e imersivas que passam a atuar sutilmente através de uma economia de investimentos, pois se fixam ideias de correto, bom, saudável, ideal etc., nas mentes de públicos específicos.

Se em 1978 já se falava em um investimento no corpo útil e dócil por meio da disciplina (FOUCAULT, 2009; 2014), hoje com a geração cyber, o investimento não é tão somente no corpo, mas principalmente, na mente (LAZZARATO, 2006). Vê-se assim, surgir mecanismos que podem modular e preparar públicos para enfrentar futuras situações. A tecnologia usada para isso não é nova, mas atualmente vem ganhando ênfase pela eficácia em simular o cotidiano de sujeitos, em suma, são os simuladores da "vida real", desenvolvidos principalmente para jogos eletrônicos. Tais tecnologias além de disseminarem o medo do esgotamento dos recursos que mantém a vida humana, o medo da perda exacerbada da vida, e outros medos, visam também treinar sujeitos para uma vida, ecológica, sustentável, consciente etc. O panorama favorece e impulsiona diversos questionamentos em torno do uso dos jogos eletrônicos, das lições ambientais promovidas pelos mesmos e dos modos de condução da conduta dos sujeitos.

\section{O governamento da vida na atualidade}

Embora as palavras de Foucault tenham sido proferidas em outra época, não deixaram de ser atuais. E cabe dizer que são atuais justamente por apontarem, de certa maneira, algo que é "perceptível" na atualidade, a saber, a expressão do poder (VEIGANETO; LOPES, 2007). Por isso, ao se refletir sobre temáticas como tecnologias, jogos eletrônicos e Educação Ambiental, surgem pistas que apontam para um entrelaçamento entre elas, pois “[...] as relações de poder são intrincadas em outros tipos de relação [...]" (FOUCAULT, 2015, p. 243). Entrelaçamento que possibilita olhar para tais temáticas como formas de governamento ${ }^{3}$ presentes neste tempo. Nesse sentido, é possível pensar a ideia de

\footnotetext{
${ }^{3}$ Conforme Veiga-Neto; Lopes (2007, p. 952), “[...] usamos governamento para designar todo o conjunto das ações - dispersadas, disseminadas e microfísicas do poder - que objetivam conduzir ou estruturar as ações.
} 
governamento também presente nos jogos eletrônicos como formas de conduzir comportamentos corretos.

Foucault (2008), ao analisar as relações de poder, passa a trabalhar em algumas de suas obras, por exemplo, em Segurança, Território e População - curso ministrado no Collège de France em 1977-1978 - com as noções de Governo, Governar e governamentalidade. Buscando sempre tematizar o sujeito e as práticas de subjetivação que o investem, o autor situa historicamente o sujeito como não sendo universal, mas sim, fabricado em um dado tempo histórico. A partir desta perspectiva, emerge uma análise das redes capilares de poder, as quais se reorganizam para fabricar verdades, sujeitos, sociedades e visões de mundo.

Na segunda metade do século XVIII, com o deslocamento do poder Soberano para o Estado, as táticas de governamentalidade agregarão uma nova tecnologia de poder. Segundo Foucault (2010, p. 203), uma tecnologia que não irá retirar a disciplina “[...] mas que a embute, que a integra, que a modifica parcialmente e que, sobretudo, vai utilizá-la implantando-se de certo modo nela, e incrustando-se efetivamente graças a essa técnica disciplinar prévia”. Para Foucault (2008, p. 143), a governamentalidade será compreendida como,

[...] o conjunto constituído pelas instituições, os procedimentos, análises e reflexões, os cálculos e as táticas que permitem exercer essa forma bem especifica, embora muito complexa, de poder que tem como alvo principal a população, por principal forma de saber a economia política e por instrumento técnico essencial, os dispositivos de segurança.

Nessa perspectiva, as noções de governo, governar e governamentalidade se articulam na ação e no exercício do poder. A governamentalidade se atualizará na contemporaneidade, por exemplo, com uso de artefatos eletrônicos e do discurso ambiental; a noção de governo também se modificará, e assim, se ligará a ação política do Estado. A ação será, “aquilo que, entre nós, costuma-se chamar de Governo - o Governo da República, o Governo Municipal, o Governo do Estado (em geral, grafado com G maiúsculo) - é essa instituição do Estado que centraliza ou toma para si a caução da ação de governar" (VEIGANETO, 2005a, p. 19, grifo do autor).

Depreende-se que a noção de governo se liga a uma outra ideia, por isso, se toma a palavra governamento no lugar de governo. E vincula-se a compreensão desenvolvida por Veiga-Neto (2011), que indica uma apropriação do Estado do vocábulo governo, o que gerou 
um deslocamento e delimitação de seu sentido em torno das instituições do Estado. O autor (2005, p. 82, grifo do autor), ainda afirma que:

[...] o uso do mesmo vocábulo para a instituição e para a ação gera, no mínimo, alguma ambiguidade. É justamente nesse ponto que passo a sugerir que o vocábulo governo - o único usado em textos foucaultianos, seja nas traduções para a língua portuguesa, seja nos textos escritos por autores de língua portuguesa - passe a ser substituído por governamento nos casos em que estiver sendo tratada a questão da ação ou ato de governar.

Ao se pensar neste deslocamento conceitual que o autor propõe, se percebe a dinamicidade com que as relações de saber e poder estabelecem de tempos em tempos. Abrese, dessa forma, possibilidades para compreender as condições que favoreceram a emergência, não apenas da noção moderna de Estado, mas também a de uma estrutura neoliberal que perpassa a invenção dos sujeitos.

Vê-se que as táticas de governamentalidade emergem na atualidade com outras formas e outras práticas de governamento, pois os mecanismos são atualizados, agrupados, integrados e redimensionados de forma estratégica para capturar sujeitos em suas mais ínfimas pluralidades. Surge, assim, o capital cognitivo, o autoempreendedorismo, a autonomia, a flexibilidade (do sujeito e do trabalho), o discurso de crise, os cálculos estatísticos que reforçam o medo do planeta acabar, das epidemias, do trânsito etc.

E se tratando de índices estatísticos, nota-se que estes possibilitam a regulação das condutas por meio do governamento do medo, pois reforçam a necessidade do treinamento para o sucesso e do aprimoramento de prática "corretas". De acordo com Lemke (2014), a visão contemporânea requer o cálculo e a estimativa permanentemente para instituir um medo constante de fracasso.

Diante deste panorama, pode-se apontar que a produção do medo serve como governamento de públicos em uma época que é atravessada por um outro modo de governamentalidade, visto que a conjuntura histórica é diferente da analisada por Foucault. A constante deste tempo se torna então a condução e o controle por meio do medo, pois afinal, o medo é o sentimento mais antigo do mundo (BAUMAN; BORDONI, 2016). A estratégia do medo torna-se chave de ouro para a fabricação de verdades e práticas de subjetivação. Nisso pode-se observar que é através do medo da perda do planeta que "os sujeitos são norteados a aderir a certo modo de vida [...]. Assim, o consumo consciente ou consumo sustentável tem se constituído como um modo de vida na atualidade líquida moderna, em que os sujeitos vivenciam a experiência do medo cotidianamente" (GARRÉ; HENNING, 2015, p. 59). 
A governamentalidade e suas primeiras táticas, analisadas por Foucault, não desaparecem, pois, "no tempo da cibercultura, o poder deixa de atuar apenas através de disciplinas e emana através de modulações e em diferentes espaços, [e diferentes sujeitos]" (HENNING et al., 2014, p. 230). Sujeitos que se constituem em públicos que ganharam o foco e passam a ser investimentos de um poder, um noopoder ${ }^{4}$. Frente a tais percepções, pode-se indicar que o discurso ambiental contido em artefatos tecnológicos, como forma de conduzir as condutas, também incidirá na mente destes públicos, buscando mobilizá-los em seu dia a dia através de ações que objetivem a preservação do futuro do planeta. Tornando-se assim, "necessário fechar a torneira quando escovar os dentes, lavar o carro economizando água, reciclar o lixo e tantas outras intervenções, que a cada dia, a mídia nos interpela, convidando-nos (ou convocando-nos?) a pensar no futuro (HENNING et al, 2014, p.236).

As ações que surgem para conduzir a si próprio e os outros, são deliberadas por uma microfísica do poder que se utiliza de ferramentas tecnológicas, por exemplo, jogos eletrônicos, para subjetivar os corpos e as mentes de públicos. Segundo Tarde (2005), se vinculam por uma simultânea convicção ou paixão, consciência que cada um deles possui de que essa ideia ou essa vontade é compartilhada no mesmo momento por um grande e diverso número de sujeitos. O público é a forma de subjetivação, conforme Lazzarato (2006, p. 77), “[...] que melhor expressa a plasticidade e a indiferença fundamental da subjetividade qualquer. Os indivíduos e os públicos não estabelecem em si uma relação de pertencimento exclusivo e identitária: [pertencem] simultaneamente a diferentes públicos (multipertencimento)".

Em uma breve análise no jogo The Sims, que é um simulador, nota-se que existe um viés ambiental que permeia o jogo. Propostas como elaboração de horta, produção de fertilizante orgânico e consumo de produtos "naturais" estão presentes no jogo para ensinarem modos de viver uma vida de "qualidade". Compreende-se tais propostas como estratégias discursivas que nos interpelam e se colocam, “[...] em relação com nossos modos de ver e entender o ambiente, a cultura, a natureza. Os ditos midiáticos vão nos ensinado as formas corretas de fazer tais leituras e condicionam nosso olhar para ver o que 'deve ser visto' e fazer o que 'deve ser feito"' (GARRÉ; HENNING, 2015, p. 61, grifo das autoras).

Na página do fabricante do jogo, onde se anuncia o seu sistema de classificação, é ressaltado seu objetivo com a seguinte informação: “[...] para educar os consumidores, pais e varejista [...]” (ELECTRONIC ARTS, 2016). O gerenciamento da conduta é endereçado a um

${ }^{4}$ Conceito que será abordado na próxima subseção. 
público, a saber, de jogadores (crianças, jovens e adultos). Os jogos são mídias potentes, pois através da imersão em ambientes virtuais, sujeitos aprendem a pensar e a lidar com diversas problemáticas, entre elas, as ambientais.

As práticas de governamento têm se configurado através de jogos eletrônicos e outras tantas ferramentas tecnológicas que possuem ampla circulação no âmbito social. Assim, o gerenciamento materializa-se em modos de se conduzir corretamente frente ao trânsito, ao meio ambiente, a si próprio e aos outros. Entende-se que tais modos configuram sujeitos em públicos que se agregam por lógicas comuns, que se ligam a tantos outros públicos em uma rede imensurável. Tarde (2005, p. 23), afirma que, "essa transformação de todos os grupos em públicos exprime-se por uma necessidade crescente de sociabilidade que torna imperiosa a comunicação regular dos associados através de uma corrente contínua de informação e de excitações comuns. Ela é, portanto, inevitável”.

Ressalta-se que embora a ênfase hoje seja o controle de públicos, não significa que não existam mais táticas direcionadas ao sujeito e à população (LAZZARATO, 2006). Assim, nota-se "intervenções na vida individual da população, o biopoder vai conduzindo as condutas da massa de indivíduos, agindo nas ações cotidianas dos sujeitos, buscando interpelar a 'cada um', [e transformando os corpos através da disciplina]" (HENNING et al., 2014, p. 236, destaques dos autores). A biopolítica, em contrapartida, com intervenções na população se mostrará em técnicas de controle da natalidade, cálculos estatísticos, campanhas de salvação do planeta Terra entre outras estratégias (FOUCAULT, 2008). Para Lazzarato (2006), os dispositivos noopolíticos ${ }^{5}$, atuam nos públicos através da imprensa, televisão, internet, jogos eletrônicos, smartphone etc., para fabricarem maneiras diferentes de atualizar e efetuar o que se diz, se pensa, se vê, se faz, se considera, em suma, controlar a opinião. Intervêm no acontecimento, na cooperação entre cérebros, na inteligência, ou seja, diferente do biopoder e da biopolítica que tem por alvo o corpo, a noopolítica toma a dimensão incorporal dos públicos.

No entanto, não se trata de uma substituição, e sim de uma atualização e inclusão de outras práticas de governamento. Uma atualização que inclui o gerenciamento do corpo, mas também, e talvez principalmente, da mente. Por isso, é possível pensar que, “[...] enquanto os dispositivos de segurança multiplicam a fabricação de riscos, os dispositivos de controle multiplicam a fabricação de públicos" (VEIGA-NETO, 2011a, p. 47). O público é uma multiplicidade que não está liga pelo espaço, e sim pelo tempo. O poder que atua na formação

\footnotetext{
${ }^{5}$ Segundo Lazzarato (2006, p. 84), “A noopolítica (conjunto das técnicas de controle) se exerce sobre os cérebros, atuando em primeiro lugar sobre a atenção, para modular a memória e a sua potência virtual”.
} 
do público não é da ordem da disciplina. Sendo assim, não existem corpos enclausurados, corpos a serem vigiados. O poder que cria o público não visa o corpo do indivíduo nem o corpo da espécie, mas sim, diretamente a alma (VEIGA-NETO, 2011a).

Nessa perspectiva, a gestão dos riscos e dos públicos são parte da propagação e a efetivação das formas neoliberais de governamento, as quais têm colaborado na produção da insegurança e do cultivo do medo, que vão além dos graus constatados por Foucault durante sua vida (LEMKE, 2014). Garantir a segurança em diversos âmbitos implica, certamente nesse contexto, em produzir estratégias que operem sobre os diferentes contextos sociais.

Assim, tais engendramentos fabricam determinados sujeitos, pois, conforme Lemke (2014, p. 118), “no contexto neoliberal, o medo é a base e o motivo para a constituição do sujeito responsável, confiável e racional. Ele tem uma qualidade civilizadora: os bárbaros não têm medo - é por isso que são tão perigosos". Os sujeitos de hoje são aglomerados em públicos, fabricados, conduzidos, gerenciados por diversos dispositivos que constituem “[...] modos de ver, de falar e de pensar sobre a questão ambiental a partir de uma trama de diferentes discursos que se engendram, sejam eles legais, midiáticos, políticos, educacionais, científicos, ecológicos ou econômicos" (GARRÉ; HENNING, 2015, p. 71).

A contemporaneidade apresenta um contexto de transição, atualização e velocidade, que se produz e se refaz constantemente. Portanto, se existe uma transição que é contínua, não há então sujeito a-histórico ou universal, como também não são as mesmas, as relações na sociedade atual. Nesse sentido, compreende-se que o pensamento de Michel Foucault fornece as ferramentas para operar num contexto diferente que se estabelece, e por sua vez, é através destas que se chega a novas ferramentas.

Atualmente se estabelecem outras relações, as quais não se fixam, portanto, são instáveis e inseguras. A homogeneização e a heterogeneização andam juntas na formação dos públicos. A vida privada se torna pública, pois as imagens falam tanto quanto as palavras. Os sujeitos isolados em casa, transformaram-se em sujeitos interligados com o mundo, através do jogo, do computador, dos martphones etc. O protesto descentraliza-se dos movimentos estudantis na universidade e começa primeiro nas redes de comunicação, sem a "cabeça" de um líder, apenas um desejo comum. A sociedade de controle, afirma Lazzarato (2006, p. 85, grifo do autor), “[...] exerce seu poder graças às tecnologias de ação a distância da imagem, do som e das informações, que funcionam como máquinas de modular e cristalizar as ondas, as vibrações eletromagnéticas (rádio, televisão), ou máquinas de modular e cristalizar os pacotes de bits". 
Foucault morreu em 1984, no entanto, o que diria dos dias atuais? Que relações de poder e que modos de subjetivação levantaria neste tempo? Pensar de outros modos as questões da atualidade, que o autor não desenvolveu, torna-se uma responsabilidade de quem se apropria deste referencial para fazer pesquisa em tempos contemporâneos. Segundo VeigaNeto e Lopes (2010, p. 150, destaques dos autores),

O "pensar de outro modo" se move a partir de uma atitude de suspeita frente a tudo aquilo que é dado e que parece óbvio e natural. O "pensar de outro modo" significa o exercício de (tentar) pensar por fora do que é dado e já foi pensado, não no sentido de ampliar seus limites, mas sim no sentido de não assumir as bases sobre as quais se assenta esse dado que já foi pensado e, dessa maneira, deixar o já pensado para trás.

$\mathrm{Na}$ esteira deste pensamento, coloca-se em suspenso os jogos e suas verdades, para ainda tensionar outras inquietações. Observa-se, assim, que os jogos eletrônicos estão atrelados a um modo de governamento que está próximo às questões do cérebro. Tomam como alvo múltiplos públicos, que são investidos por uma outra tecnologia de poder, a qual Lazzarato (2006), denominou de "Noopolítica". As tecnologias e os jogos eletrônicos, portanto, descrevem os modos de vida na atualidade e uma nova ordem de poder que se exerce nos públicos.

\section{Noopolítica e jogos eletrônicos}

Na seção anterior, delineou-se o conceito de governamento e algumas práticas de condução da vida na atualidade. Vê-se então, que se tece um jogo de forças e de embates que são travados entre, “[...]nós, indivíduos já subjetivados pelo discurso do 'ecologicamente correto', acabamos persuadidos a participar dessa rede discursiva em prol do planeta! Não basta que sejamos interpelados pelo medo da catástrofe; [é preciso] uma atitude responsável!" (GARRÉ; HENNING, 2014, p. 433).

A sociedade passa a ser interpelada constantemente pelo espectro da insegurança. Suas marcas se refletem nas formas de ver e se conduzir no mundo em que se vive. As sombras das incertezas atormentam para assinalar e demarcar a posição dos sujeitos neste tempo. Uma rede discursiva cheia de enunciações de medo que se instaura para "[...] regular a vida atingida pela doença, pelo desemprego, pela velhice, pela morte, [e pelas catástrofes ambientais][...]. As técnicas de controle voltam-se, assim, para a vida, mas em um sentido completamente diferente" (LAZZARATO, 2006, p. 81). 
O medo se vincula a artefatos interligados a redes de comunicação, que promovem opiniões e visões sob o que somos e o que devemos ser. Jogos eletrônicos ensinam como gerenciar os recursos naturais e a medir os impactos da ação do homem no meio ambiente. Com a emergência dessa tão disseminada crise ambiental, desponta a cobrança cada vez mais acentuada de sua divulgação e da conscientização dos sujeitos. "O medo não somente estimula a consciência dos riscos econômicos e das incertezas que acompanham o empreendedorismo social esperado, ele também é um meio importante de medicalização e genetização da sociedade" (LEMKE, 2014, p. 117, grifo nosso).

Nota-se que essa "consciência" é precedida por um pensamento contemporâneo, cuja lógica alinha-se a que Deleuze (1976) entende por "niilismo reativo"6 ou "consciência reativa" (VEYNE, 2008) ou ainda uma "má consciência"” (NIETZSCHE, 2009). Os sujeitos que apresentam uma consciência reativa não tomam determinadas ações, porque em suas concepções estão fazendo algo "errado". Desse modo, os sujeitos ecológicos não fazem determinadas ações, consideradas incorretas, por entender que estão ferindo seus valores ecológicos.

Uma consciência reativa pode ser fabricada por diversos artefatos que reforçam um panorama de crise e incerteza. Artefatos que ratificam modos de agir ou, como aponta Veyne (2008, p. 131) ao comentar Foucault, tornam possível a “objetivação de práticas determinadas". Nesse sentido, uma autoconsciência rege as condutas dos sujeitos através do medo e da culpabilização. O que, consequentemente, potencializa a existência de um ideal de sujeito, com determinadas características, virtudes e valores. Nietzsche (2005, p. 24, grifo do autor), aponta que,

[...] como, na grande maioria dos casos, só houve querer quando se podia esperar também o efeito da ordem - isto é, a obediência, a ação -, a aparência traduziu-se em sensação, como se aí houvesse uma necessidade de efeito; em suma, o querente acredita, com elevado grau de certeza, que vontade e ação sejam, de algum modo, a mesma coisa - ele atribui o êxito, a execução do querer, à vontade mesma, e com isso goza de um aumento da sensação de poder que todo êxito acarreta.

Os sujeitos em questão, agem por que são afetados por uma verdade, a de que o mundo está em crise. Assim, precisam ter práticas política e ecologicamente corretas, senão suas ações poderão acarretar na futura destruição do planeta e da humanidade. Nessa

\footnotetext{
${ }^{6}$ Deleuze (1976, p. 69, destaques do autor), ao discorrer sobre a obra de Nietzsche comenta que o segundo sentido do Niilismo é o "[...] 'pessimismo da fraqueza', [que] encontra seu princípio na vida reativa nua e crua, nas forças reduzidas a si mesmas. É um niilismo reativo".

${ }^{7}$ Segundo Nietzsche (2009, p. 48, grifo do autor), "[...] 'coisa sombria', a consciência da culpa [...]".
} 
perspectiva, volta-se ao pensamento de Nietzsche (2009, p. 64, grifo do autor), o qual ao explanar sobre a "má consciência", afirma que, “[...] de fato, por muitíssimo tempo os que julgavam e puniam não revelaram consciência de estar lidando com um "culpado". Mas sim com um causador de danos, com um irresponsável fragmento do destino".

O medo é incutido nas mentes contemporâneas, que passam a receber a cada segundo incontáveis informações, que chegam por meio de diversas tecnologias. Vê-se que, se as disciplinas produziam corpos através de hábitos, especialmente na memória corporal, as sociedades de controle modulam os cérebros, fabricando hábitos sobretudo na memória mental (LAZZARATO, 2006).

Nesse sentido, o gerenciamento da vida se configurará através de uma forma sutil, e por que não, até "prazerosa", de normatizar e conduzir a conduta de múltiplos sujeitos distribuídos em públicos. "Essa nova forma de poder incide sobre a vida, mas não a vida no sentido de bios nem de zoé, dos fenômenos biológicos, mas a vida, conforme definem Tarde e Bergson: a vida como memória” (VEIGA-NETO, 2011a, p. 47, grifo do autor). Percebe-se então, emergir um poder que atua na formação dos públicos, o qual Maurizio Lazzarato (2006), denominou de noopolítica. Veiga-Neto (2011, p. 17), comenta que:

De certo modo inspirado no conceito foucaultiano de biopolítica, mais recentemente Maurizio Lazzarato propôs o conceito de noopolítica para caracterizar a maneira pela qual, a partir das últimas décadas, se buscou racionalizar os problemas colocados (para a prática governamental) pelos fenômenos próprios da interpelação cultural, da memória, da atenção, do desejo, do controle etc. Com esse neologismo, Lazzarato aponta para o conceito aristotélico de "intelecto" - o noûs -, como a parte mais elevada da alma, em oposição à percepção sensorial, que é da ordem do nosso corpo material.

O noopoder é um poder que incide na memória, consciência, atenção, pensamento, produtividade intelectual e na flexibilidade do sujeito. Portanto, a noopolítica se configurará em táticas que atuarão sobre os públicos para modulação das "[...] mentes com o objetivo de formar aquilo que se conhece por opinião pública" (VEIGA-NETO, 2011a, p. 47). Coadunados, o noopoder e a noopolítica, tomam por alvo aquilo que, talvez, o biopoder e a biopolítica não consigam capturar, o homem-espírito, o qual, de acordo com Foucault, somente é objeto do biopoder no limite, pois passará a estar primeiro plano (LAZZARATO, 2006).

As possibilidades de fabricar, neste tempo, sujeitos mais "inteligentes", são potencializadas por doses diárias de estímulos advindos também de jogos eletrônicos. Sendo assim, existe uma moldagem dos corpos, segundo Lazzarato (2006, p. 86), “[...] garantida 
pelas disciplinas (prisões, escola, [...]), a gestão da vida organizada pelo biopoder (políticas de saúde, [...]) e a modulação da memória e suas potências virtuais reguladas pela noopolítica (construção da opinião pública, da percepção e da inteligência coletiva[...])”. A sensação produzida por estes artefatos no cérebro chega como doses de uma droga, causando os mais diferentes sentimentos. As técnicas de poder ganham um novo foco na atualidade, a saber, produzir sujeitos que serão capazes de solucionar e gerenciar os problemas cotidianos. Para Veiga-Neto (2011b, p. 17, grifo do autor),

Nas sociedades normalizadoras, o biopoder toma a população como o objeto principal, a fim de promover a vida da espécie como bios. Nas sociedades de controle, o noopoder toma os cérebros, imprimindo diretamente neles determinados hábitos e desejos em suas memórias mentais. Com isso, o noopoder mexe com as nossas vontades e nossas condutas. Isso não significa, é claro, a demissão da disciplina e da norma nas sociedades de controle, mas a sua subordinação às técnicas de controle que se organizam e agem na forma de noopolíticas.

A capacidade de memória e de atenção “[...] tornam-se forças sociais e econômicas que devem ser capturadas para que se possa controlar e explorar o gerenciamento da diferença e da repetição" (LAZZARATO, 2006, p. 84). Entre as diversas tecnologias da atualidade os jogos eletrônicos destacam-se pela forma de capturar a memória e a atenção e produzir modos de governamento das condutas de uma multiplicidade de sujeitos. Segundo Mendes (2006, p. 25),

[...] diversas técnicas de governo funcionam por meio dos jogos eletrônicos, organizadas em estratégicas de poder-saber, formando um campo estratégico de atuação sobre o sujeito-jogador, e, igualmente, um campo estratégico de atualização do jogador sobre si mesmo, que articula não só técnicas orientadas para fabricar um tipo de subjetividade, mas da mesma forma, articula técnicas de administração dessa subjetividade. Em síntese, o sujeitojogador é uma invenção das relações de poder-saber e de um campo estratégico que constituem os jogos eletrônicos como artefatos de governo da conduta.

O jogo é um artefato que não é neutro, pois também é transpassado por relações de poder e por discursos de crises que circundam neste tempo. Relações e discursos que permeiam e atravessam a vida social modulando e fabricando memórias visuais, que se ligam aos mais diferentes públicos. Memórias que são fabricadas por um repertório de imagens de destruição e benevolência humana, que marcam, educam e projetam ideais. "A captura, o controle e a regulação da ação a distância das mentes entre si se faz através da modulação dos fluxos de desejo e de crenças e das forças (a memória e a atenção) que as fazem circular entre os cérebros, na cooperação" (LAZZARATO, 2006, p. 84). 
As demandas sociais se atualizaram, agora é imprescindível que se saiba resolver problemas, também ambientais, de forma inteligente, ou seja, com baixos custos econômicos e menos uso de recursos naturais. Para isso, deve-se promover o exercício mental, a fim de se fabricar mentes inteligentes, flexíveis e dinâmicas, que saibam solucionar de forma criativa as problemáticas deste tempo. Produzindo, por sua vez, um ambiente que utiliza tecnologias de ponta para construir um mundo mais equilibrado e saudável aos seres humanos.

Nesse sentido, é indispensável dominar as tecnologias da informação, visto que é um dos meios por onde os discursos e os enunciados incidem sobre os públicos. Lazzarato (2008, p. 46), indica que, "da espécie aos públicos, temos aí todo um campo de realidades novas, de novas maneiras de agir sobre os comportamentos, sobre as opiniões, sobre as subjetividades, para modificar as maneiras de dizer e de fazer dos sujeitos econômicos e dos sujeitos políticos". Assim, o homem "civilizado", da atualidade é aquele cuja memória é da empregabilidade, da disponibilidade, da docilidade às leis do mercado de trabalho e do consumo, pois ele lhe é devedor de um crédito (LAZZARATO, 2011).

Em se tratando dos discursos que circulam na sociedade, pode-se indicar uma ligação entre governamento, noopolítica, niilismo reativo, jogos eletrônicos e os processos de subjetivação no campo da Educação Ambiental. Dessa forma, “[...] os discursos ambientais misturam quase indistintamente conhecimentos e saberes [...]" (VEIGA-NETO, 2011b, p. 18). Ainda conforme o autor,

Se para o governamento biopolítico das populações eram os planejadores, os políticos e os experts que recorriam aos conhecimentos científicos para garantir da melhor maneira o fazer viver e deixar morrer, para o governamento noopolítico parece que, além deles, todos nós somos instados a nos aparelhar e, na medida do possível, darmos conta de nós mesmos. (p.19, grifo do autor).

Nessa perspectiva, o governamento, em tempos atuais, efetua-se através do noopoder, que imprime determinados hábitos e desejos nas memórias mentais. Surge, assim, na contemporaneidade um "querer ser ecológico", uma consciência ambiental, uma consciência reativa e ações ecológicas, que se ligam ao mundo dos negócios. Observa-se que somos convocados à participação, a interatuação e à conectividade. Para com isso, "treinar os sujeitos contemporâneos", nutrindo e incutindo nos nossos corpos e mentes modos de ser mais “adequados ao projeto político e econômico" da sociedade (GUIMARÃES, 2011).

Do homem-corpo para o homem-espécie, e por sua vez, ao homem-espírito, haverá adaptações nas formas de governamento da vida. Percebe-se, assim mudanças e engendramentos que se estabelecem para atuar sobre os sujeitos e os públicos. Em meio a um 
mundo tecnológico, despontarão os discursos de preservação do planeta instituído por uma disputa de poder silenciosa, onde cada centelha é uma verdade que emerge. O que se verifica, por sua vez, são as novas formas de captar e capturar os sujeitos que tentam escapar dessa malha de poder, na qual os jogos eletrônicos funcionam como táticas de controle mental. Apreendendo a atenção e a memória, os jogos passam a ensinar educações ambientais, visto que também se apoderam dos discursos que permeiam a sociedade. Assim, enunciações de medo e de crise aparecem associadas a relações de consumo e a produção de subjetividades. Uma noopolítica entra em funcionamento para regular e modular consciências ambientais e reativas de públicos.

Diante do discorrido até aqui, evidencia-se as novas formas de governamento da vida, por meio de tecnologias, que promovem e introjetam ideais ambientais. Percebe-se, assim, surgir outra tática que se vincula à biopolítica e passa a se destacar nesta conjuntura de saber e poder ou em uma ecogovernamentalidade (MALETTE, 2011). Táticas que se unem a noopolítica para fabricar ações de governamento do planeta, as quais Edson Passetti (2013), chamou de Ecopolítica. Nesse sentido, pode-se pensar que, se existem novas subjetivações, quais ideais ambientais têm se instaurado neste tempo?

\section{Ecopolítica: que ideias tem se tornado fixas?}

A emergência da crise ambiental, o advento das tecnologias e as novas relações com o saber, se ligam aos meios de produção e consumo, para apontarem a iminência em se repensar os vínculos que o ser humano estabeleceu com o ambiente. As novas contingências e a atualização das técnicas de operação do poder apontam para o surgimento de uma “ecogovernamentalidade" (MALETTE, 2011), que se configura por uma "ecopolítica" (PASSETTI, 2013). Malette (2011, p. 5, grifo do autor), argumenta que,

[...] a emergência da "ecogovernamentalidade" pode ser compreendida como a intensificação e transformação da "lógica imanente" que reorganiza as suposições dualísticas e derivativas incorporadas ao nosso entendimento do político. Meu principal argumento é que os estudos da governamentalidade deveriam reconhecer a "ecopolítica" como uma das principais racionalizações de governo para o século XXI.

Pensar este tempo sob o viés de uma ecogovernamentalidade é ampliar os conceitos foucaultianos. É olhar para as condições que propiciam o surgimento e a efetivação de novas práticas de governamento da vida no planeta, a saber, uma ecopolítica. Passetti ao perceber as 
transformações atuais faz um deslocamento do conceito de "biopolítica" (FOUCAULT,2010a), para uma ecopolítica, a qual busca relacionar a produção de verdade capitalista sustentável. A noção de ecopolítica intenta responder algumas das novas institucionalizações deste tempo. Trata-se, então, de "[uma] prática de governo do planeta nos tempos de transformação (de si, dos outros, da política, das relações de poder e do planeta no universo), com desdobramentos transterritoriais e variadas estratificações conectadas" (PASSETTI, 2013, p. 10, grifo do autor).

Nesse sentido, o trabalho de Foucault é de central relevância na análise da fabricação e propagação de saber, de tecnologias e nas racionalidades de governamento que empregam a noções de "natureza” para moldar visões e modos de pensar. É possível, deste modo, “[...] inscrevermos a ecopolítica no marco da governamentalidade neoliberal, de modo a falarmos de uma ecogovernamentalidade como extensão e atualização da governamentalidade liberal ou (digamos) 'clássica”” (VEIGA-NETO, 2014, p. 41, grifo do autor).

O conceito de biopolítica desenvolvido por Foucault (2008a), tem por alvo a população ou o corpo-espécie, porém, hoje "a população não é só pensada e calculada como espécie humana. Ela é também público como conjunto de opiniões, hábitos e maneiras de ser [...]" (PASSETTI, 2013, p. 5, grifo do autor). Diante destas "novas" organizações da população, é possível pensar que as formas de governamento da vida se dão num alcance ainda maior.

Pode-se dizer que a ecopolítica não apenas desloca a importância até agora conferida à biopolítica como, também e principalmente, amplia, do humano para o planetário, o papel conferido à vida. Assim, nossos interesses e preocupações com a manutenção da vida vão para além da população humana (como corpo-espécie) e se instalam no todo do planeta (como um novo corpo vivo, digamos um corpo-ecológico ou um corpo-planetário). (VEIGA-NETO, 2014, p. 41, grifo do autor).

Nessa perspectiva, pode-se apontar que as técnicas ecopolíticas se mostram efetivas e atuantes na contemporaneidade. "Questões tais como consciência ecológica, preservação do planeta, minimização dos partidarismos, segurança, respeito às diferenças etnoculturais, atenção às necessidades locais, sustentabilidade e antiutilitarismo constam nas agendas da ecopolítica" (VEIGA-NETO, 2014, p. 40).

O cenário que se estabelece, passa a requerer novas soluções, modos de compreender a diversidade ecológica em termos do valor inerente da "vida" e de circunstâncias possíveis de redes colaborativas descentralizadas capazes de transcender os modelos instituídos de relações hierárquicas. A biopolítica e a governamentalidade abrem espaço “[...] à captura das 
energias inteligentes a serem ocupadas nas conformações computo-informacionais, sob o controle do planeta por ecopolíticas e a [ecogovernamentalidade] das novas condutas" (PASSETTI, 2011, p. 131).

Em um mundo globalizado, considerar as relações entre a territorialidade e a ecogovernamentalidade passa a ter maior relevância, pois não se trata apenas de repensar as agressões que a lógica capitalista tem realizado ao ambiente, em termos de esgotamento e contaminação. Trata-se, também, de considerar a própria lógica espacial de desterritorialização em que o capitalismo atua, em suas novas disposições na atualidade (VEIGA-NETO, 2014). As relações de poder que se configuram em redes passam a ocorrer por fluxos contínuos que se relacionam um com outro, para elaborarem virtualidades, revestirem mobilidades e posicionam um gerenciamento em espaços contínuos de comunicação. Nessa conjuntura, novas verdades são constituídas, ideias se tornam fixas e fabricações possíveis efetivam-se, pois como evidencia Passetti (2013, p. 12, grifo do autor):

A reviravolta nas pretensões capitalistas com base no desenvolvimento sustentável evidencia que o alvo não é mais manter a condição de pobreza, mas elevar os indicadores econômicos, auferir índices de felicidade e desenvolvimento humano (saúde, educação e cultura), disseminar uma cultura de paz, educar pessoas e práticas para a resiliência, instituir uma economia verde, encontrando certa qualidade de vida com redutores de vulnerabilidades e gerando condições compartilhadas para uma vida melhor de pessoas, ares, mares, relevos, florestas, enfim, do ambiente. Trata-se de um investimento na ocupação de inteligências, em participações, conexões, múltiplas identificações, assentamento de direitos, segurança e securitização, conservação do planeta que requer, antes de tudo, moderação, e o meio encontrado para tal condição está na vida resiliente.

Cria-se o livre mercado, a circulação em rede, o consumo em massa, para a manutenção das condições ambientais exigidas por alguns nichos de sujeitos, os quais são como "sepulcros caiados de verdes". Estes instauram discursos ecoamigáveis de gerenciamento dos recursos naturais, endereçados a grande parcela da sociedade, a qual se fragmenta, diversifica e se pluraliza em públicos. Nota-se que existe na sociedade algo como um efeito placebo, fabricado num mundo cyber, que se institui pelo discurso do acesso "igual para todos", de "todos" com poder de compra, de "estado de crise" onde "todos" são responsáveis pelo planeta. "Não está mais em jogo como conter energias políticas de um corpo útil exaurido pela mecânica, mas como expandir suas energias inteligentes dedicadas a provocar inventividades programáticas" (PASSETTI, 2011, p. 133). Vê-se, assim, "vozes" que conclamam, comovem e se dispõem a mudança de atitudes, porém são as mesmas que no silêncio destroem em nome do bem-estar da sociedade. 
A sociedade de controle, enfim, escancara em cada um a realização da utopia da transparência, seja pela imagem disseminada a todos pela internet, seja pela exposição da vida por blogs, twitter ou Orkut e derivados de comunidades virtuais [comunidades de jogos online], até mesmo pelos programas de comunicação contínua como os Live Messengers. Todos devemos e podemos participar, nos exibir por dentro e por fora: estamos convocados a participar (idem).

Os discursos que se configuram, visam conscientizar e potencializar as inteligências dos sujeitos para solucionar problemas ambientais, a fim de que não se perca o planeta. Os jogos eletrônicos, também fazem parte desta rede discursiva que fabrica visões, formas de pensar e agir. Estão presentes em plataformas, como smartphones, tablets, iPads, consoles etc., que se interligam às redes de comunicação. "A produção de inteligência funciona por meio de programação organizadas por interfaces e deve às práticas diplomáticas em protocolos a projeção da efetivação de melhorias para um futuro melhor para as gerações [...]" (PASSETTI, 2013, p. 15, grifo do autor).

$\mathrm{O}$ ar de suspeita recai, por sua vez, sobre as diversas "almas boas" e "amantes da natureza", que buscam ensinar, educar e conscientizar outras "pobres almas" para um mundo melhor. E se suspeita principalmente porque "hoje, os interesses desinteressados da sociedade civil passam a compor com os interesses da economia política, por meio das conexões inacabadas entre divíduos e as variadas comunidades em torno do futuro melhor para as gerações" (PASSETTI, 2013, p. 15, grifo do autor).

No caso de campanhas, pode-se indicar uma que vem "sensibilizando" a muitos, a saber, a campanha lançada em 2015 pela empresa Unilever Brasil, intitulada "adeus florestas" (UNILEVER BRASIL, 2015). Ela tem como meio disseminador um vídeo, onde uma árvore migra da floresta para a cidade. Nesse trajeto passa por diversas pessoas admiradas por verem uma árvore caminhando. O vídeo ganha um ar melancólico com uma música de fundo e a voz do narrador que retrata o pensamento da árvore. Na narrativa duas frases chamam a atenção: "Nunca pensei que em meus mil anos poderia estar mais segura na cidade."; e "Somente nós podemos mudar isso." (referindo-se as pessoas). A comoção e a sensibilização dos sujeitos podem ser percebidas nos comentários dos internautas que visualizam o vídeo no YouTube. A relação entre empresários, Estado e organizações internacionais com as várias comunidades, segundo Passetti (2013, p. 23), “[...]busca solidificar, plasticamente, um mundo melhor, que deve funcionar como redutor e/ou interceptador de resistências. Trata-se, agora de uma intervenção não mais para a sujeição, mas uma intervenção ambiental”. 
Pode-se perceber a articulação de novos elementos de "[...] distinções operando para tornar convincentes as justificativas de empreendimentos ecológicos disciplinadores/reguladores e a produção de um conceito mais inclusivo pelo qual a regulação dos vivos pode, de fato, expandir-se para tudo o que é necessário para a vida [...]" (MALETTE, 2011, p. 20-21). A articulação entre um saber particularizante e a mútua relação dos sujeitos por um globalizador e quantitativo concernente à população, é utilizado para a decomposição de ambos através da circulação e da convocação à participação. Assim, muitos colaboram para a manutenção de um modelo ambiental.

Diante do exposto, vê-se que o discurso com um viés ambiental prolifera e transita por inúmeros âmbitos na contemporaneidade. Discurso que se liga a táticas ecopolíticas que se espraiam por eletrônicos, campanhas de conscientização ambiental etc. Nesse sentido, Passetti (2013, p. 32, grifo do autor), contribui com a seguinte colocação:

No interior dos Estados, projetos conectando conservação da natureza e populações locais (indígenas ou ribeirinhas) começam a tratá-las por meio de gestão territorial combinada com economia verde, ainda voltada a bens de consumo de preços altos a setores da sociedade com elevado padrão aquisitivo e portadores de consciência ambiental; nas áreas urbanas, restaurações de espaços degradados, inclusão de populações periféricas com incentivos à participação nas decisões locais, ampliando as tecnologias sociais em negócios sociais, com a presença dos stakeholders, e dão novos contornos que ultrapassam a requerida responsabilidade social proposta por empresários ambientalistas.

Com isso, vê-se desenhar um panorama das relações de poder que se estabelece neste tempo. As articulações e atualizações que marcam as novas formas de governamento da vida instituídas hoje. E no que se refere à "[...]ecopolítica e à ecogovernamentalidade, há muita coisa ainda por fazer. Arriscamo-nos a sugerir que uma parte deste "ainda por fazer" poderá ser facilitado se nos valermos dos avanços já conseguidos nas muitas discussões já travadas em torno da biopolítica e da governamentalidade" (VEIGA -NETO, 2014, p. 45, grifo do autor).

\section{Considerações finais}

Ao se pensar neste fazer, buscou-se realizar as aproximações e deslocamentos dos conceitos foucaultianos. Todavia, cabe ressaltar que os conceitos não são universais, mas sim, retratam e dizem respeito a uma determinada sociedade. Portanto, é através da atualização destes que se torna viável olhar para uma noopolítica e uma ecopolítica e para as práticas de 
ecogovernamentalidade, as quais somente são perceptíveis por meio de uma governamentalidade neoliberal que é pujante neste tempo. Assim, "acompanhar Foucault, andar com Foucault, seguir suas sugestões e dele se apartar, em silêncio. Um silêncio na caminhada. Retomar Foucault sem pretender a exegese e proceder por conta própria. Acompanhar um texto, uma genealogia e avançar” (PASSETTI, 2011, p. 127).

$\mathrm{Na}$ esteira desse pensamento, o presente artigo teve o intuito de evidenciar as relações de poder existentes neste tempo. Foi na companhia, por vezes distante, de Foucault que se olhou para um poder que atua na modulação da memória e da atenção, com o objetivo de fabricar "consciências" responsáveis, flexíveis etc., de artefatos tecnológicos que capturam e subjetivam públicos. Públicos estes que são interpelados, convocados pela estatística do medo, por campanhas de conscientização ambiental e por jogos eletrônicos que educam para ações futuras.

Diante de tais engendramentos vê-se a relevância de pensar em uma Educação que se preocupe com as problemáticas vividas pela sociedade em tempos atuais. As questões ambientais é uma dessas problemáticas. Por isso, entendemos que trazer a Educação Ambiental para ser pensada junto ao Minecraft pode ser uma importante ferramenta para tensionar nossos modos de ver, sentir e viver nossas relações com a natureza e as relações que estabelecemos com o meio ambiente. É dessa provocação que podemos dar potência aos nossos modos de educar e viver as problemáticas ambientais que invadem nosso cotidiano. $\mathrm{E}$ a Educação não pode se furtar dessa tarefa!

Nesse viés se perseguirá as fabricações dos sujeitos na contemporaneidade, aqueles que são constituídos pelos discursos ambientais, educacionais e culturais de nosso tempo. E no bater e se debater das inquietudes mobilizadas por provocações, se instaura o silêncio diante do tilintar das espadas em batalha. Mas "andar em silêncio com Foucault, nestes dias de moderação e capital humano, talvez seja para pronunciar uma revolta [...]" (PASSETTI, 2011, p.140). Uma pequena revolta diária!

\section{REFERÊNCIAS}

BAUMAN, Zygmunt; BORDONI, Carlo. Estado de crise. Rio de Janeiro: Zahar, 2016.

DELEUZE, Gilles. Nietzsche e a filosofia. Rio de Janeiro: Rio, 1976.

ELECTRONIC ARTS. Site Oficial. Disponível em:〈http://www.ea.com/about>. Acesso em: 11 jul. 2016. 
FOUCAULT, Michel. Ditos e escritos III: Estética: literatura e pintura, música e cinema. 2 ed. Rio de Janeiro: Forense Universitária, 2009.

FOUCAULT, Michel. Ditos e escritos IV: Estratégia, Poder-Saber. Rio de Janeiro: Forense Universitária, 2015.

FOUCAULT, Michel. Em defesa da sociedade. São Paulo: Martins Fontes, 2010.

FOUCAULT, Michel. O nascimento da biopolítica. Lisboa/Portugal: Edições 70, 2010a.

FOUCAULT, Michel. Segurança, território, população: Curso dado no collège de France (1977-1978). São Paulo: Martins Fontes, 2008.

FOUCAULT, Michel. Vigiar e punir: nascimento da prisão. Petrópolis: Vozes, 2014.

GARRÉ, Bárbara Hees; HENNING, Paula Corrêa. Modos de atualizar o enunciado catastrófico do planeta terra na revista veja. ETD-Revista Educação Temática Digital. Campina, SP, v. 16, n. 3, p.426-439, set.-dez. 2014. Disponível em: <http://www.fe.unicamp.br/revistas/ged/etd/article/view/6792>. Acesso em: 27 ago. 2016.

GARRÉ, Bárbara Hees; HENNING, Paula Corrêa. Visibilidades e Enunciabilidades do Dispositivo da Educação Ambiental: A Revista Veja em Exame. ALEXANDRIA Revista de Educação em Ciência e Tecnologia. Campina, SP, v. 8, n. 2, p. 53-74, junho, 2015. Disponível em: <http://dx.doi.org/10.5007/1982-5153.2015v8n2p53>. Acesso em: 29 ago. 2016.

GUIMARÃES, Leandro Belinaso. Imagens da sustentabilidade em um mundo sem ilhas. In: HENNING, Paula; RIBEIRO, Paula Regina; SCHMIDT, Elisabeth (Org.). Perspectivas de investigação no campo da educação ambiental \& educação em ciências. Rio Grande: FURG, 2011.

HENNING, Paula Corrêa et al. Educação Ambiental e Discurso: estratégias biopolíticas e produção de verdades. Revista Educação em Foco. Juiz de Fora, v. 19 n. 1 p. 221-241, mar.jun. 2014. Disponível em: <www.ufjf.br/revistaedufoco/files/2015/07/Ed-Foco-v19-n1mar14-jun14-final.pdf>. Acesso em: 27 ago. 2016.

LAZZARATO, Maurizio. As revoluções do capitalismo. Rio de Janeiro: Civilização Brasileira, 2006.

LAZZARATO, Maurizio. Biopolítica/Bioeconomia. In: PASSOS, Izabel c. Friche (org.). Poder, normalização e violência: Incursões foucaultianas para a atualidade. Belo Horizonte: Autêntica, 2008.

LAZZARATO, Maurizio. O governo das desigualdades: crítica da insegurança neoliberal. São Carlos: EduFSCar, 2011.

LEMKE, Thomas. Os riscos da segurança: liberalismo, biopolítica e medo. In: AVELINO, Nildo; VACCARO, Salvo (org.). Governamentalidade, Segurança. São Paulo: Intermeios; Brasília: CAPES, 2014. 
MALETTE, Sébastien. Foucault para o próximo século. Ecopolítica, São Paulo, n. 1, p.4-25, 2011. Disponível em: <http://revistas.pucsp.br/index.php/ecopolitica/article/view/ 7654/5602 >. Acesso em: 27 ago. 2016.

MENDES, Cláudio Lúcio. Jogos eletrônicos: Diversão, poder e subjetivação. Campinas, SP: Papirus, 2006.

NIETZSCHE, Friedrich. Humano, demasiado humano: um livro para espíritos livres. São Paulo: Companhia das Letras, 2005.

NIETZSCHE, Friedrich. Para a genealogia da moral: uma polêmica. São Paulo: Companhia das Letras, 2009.

PASSETTI, Edson. Ecopolítica: procedência e emergência. In: CASTELO BRANCO, Guilherme; VEIGA-NETO, Alfredo (org.). Foucault: filosofia \& política. Belo Horizonte: Autêntica, 2011.

PASSETTI, Edson. Transformações da biopolítica e emergência da ecopolítica. Ecopolítica, São Paulo, n. 5, p. 2-37, jan.-abr. 2013. Disponível em: <http://revistas.pucsp. br/index.php/ecopolitica/article/view/15120>. Acesso em: 25 ago. 2016.

TARDE, Gabriel. A opinião e as massas. 2. ed. - São Paulo: Martins Fontes, 2005.

UNILEVER BRASIL. Adeus florestas. 2015. Disponível em: <https://www. youtube.com/watch?v=NQjja0xP1Kw>. Acesso em: 23 set. 2016.

VEIGA-NETO, Alfredo. Ecopolítica: um novo horizonte para a biopolítica. REMEA Revista Eletrônica Mestrado em Educação Ambiental. E - ISSN 1517-1256, V. Especial, dez/2014. Disponível em: <https://www.seer.furg.br/remea/article/view/4860>. Acesso em: 26 set. 2016.

VEIGA-NETO, Alfredo. Foucault \& a Educação. 3. ed. Belo Horizonte: Autêntica Editora, 2011.

VEIGA-NETO, Alfredo. Governamentalidades, neoliberalismo e educação. In: CASTELO BRANCO, Guilherme; VEIGA-NETO, Alfredo (org.). Foucault: filosofia \& política. Belo Horizonte: Autêntica Editora, 2011a.

VEIGA-NETO, Alfredo. Educação em Ciências e Biopolítica, Educação Ambiental e Noopolítica. In: HENNING, Paula C.; RIBEIRO, Paula Regina C.; SCHMIDT, Elisabeth B. (Org.). Perspectivas de investigação no campo da Educação Ambiental \& Educação em Ciências. Rio Grande: FURG, 2011b. p. 9-21.

VEIGA-NETO, Alfredo. Governo ou Governamento. Revista Currículo sem Fronteiras, v. 5, n. 2, pp.79-85, jul./dez. 2005. Disponível em:<http://www.curriculosemfronteiras. org/vol5iss2articles/veiga-neto.pdf >. Acesso em: 10 jul. 2016. 
VEIGA-NETO, Alfredo. Coisas do governo.... In: RAGO, Margareth; ORLANDI, Luiz B. Lacerda; VEIGA-NETO, Alfredo (org.). Imagens de Foucault e Deleuze: Ressonâncias nietzschianas. 2. ed. Rio de Janeiro: DP\&A, 2005a.

VEIGA-NETO, Alfredo; LOPES, Maura Corcini. Inclusão e governamentalidade. Revista Educação \& Sociedade. Campinas, v. 28, n. 100, set./dez. 2007. Disponível em: <http://www.scielo.br/pdf/es/v28n100/a1528100.pdf>. Acesso em: 10 jul. 2016.

VEIGA-NETO, Alfredo; LOPES, Maura Corcini. Para pensar de outros modos a modernidade pedagógica. EDT - Educação Temática Digital. Campinas, v. 12, n. 1, p. 147166, jul./dez. 2010. Disponível em: <https://www.fe.unicamp.br/revistas/ged/etd /article/view/2311/2567 >. Acesso em: 10 jul. 2016.

VEYNE, Paul. Como se escreve a história; Foucault revoluciona a história. 4. ed. Brasília: $\mathrm{UnB}, 2008$.

ZERO HORA-NOTÍCIAS. Escolas usam os games para ensinar. 23/02/2013. Disponível em: <http://zh.clicrbs.com.br/rs/noticias/noticia/2013/02/escolas-usam-os-games-paraensinar-4053223.html>. Acesso em: 12 jun. 2016.

\section{SOBRE AS AUTORAS}

\section{Elisângela Barbosa Madruga}

Mestre em Educação Ambiental pela Universidade Federal do Rio Grande (FURG). Integrante do Grupo de Pesquisa Educação, Cultura, Ambiente e Filosofia (GEECAF). Email: elisangelamadruga@ outlook.com

\section{Paula Corrêa Henning}

Doutora em Educação pela Universidade do Vale do Rio dos Sinos (UNISINOS). PósDoutorado em Filosofia pela Univeridad de Murcia/Espanha (Estágio Sênior Capes). Pesquisadora do Instituto de Educação e dos Programas de Pós-graduação em Educação Ambiental e Educação em Ciências da Universidade Federal do Rio Grande (FURG). Editora adjunta da Revista Eletrônica do Mestrado em Educação Ambiental. Líder do Grupo de Pesquisa Educação, Cultura, Ambiente e Filosofia (GEECAF/FURG). Bolsista Produtividade 2 do CNPq. E-mail: paula.c.henning@gmail.com 